\title{
Asbestos associated tumours in car mechanics
}

\author{
B J ÄRVHOLM, J BRISMAN \\ From the Department of Occupational Medicine, Sahlgren Hospital, S-41266 Gothenburg, Sweden
}

Asbestos in brake linings and clutches is considered to be a major source of asbestos exposure to the general public. Nevertheless, the asbestos exposure to the car mechanics from this source during repair of brakes and clutches is several times higher. It has been suspected that the exposure may cause lung cancer or mesothelioma in car mechanics and the union asked for an investigation. To study this subject we used linkages between the census of 1960 in Sweden and the Swedish Cancer Register and the Swedish Death Register respectively. This is a report on the preliminary findings.

\section{Methods}

The census of 1960 contains information about occupational title and industrial category in 1960 . We used "mechanic" as the occupational title (code 752) and "car repair" as the industry (code 354). According to this selection procedure the census contained in total 21905 men (table 1).

The Swedish Death Register contains all Swedes who have died since 1952 and the underlying cause of death according to the death certificates. A linkage between the death register and the census is commercially available. It gives the observed number of cases 1961-73 for a certain diagnosis and the expected numbers calculated from death rates of the general population. The linkage between the Swedish Cancer Register and the census includes the years 1961 to 1979 and is called the Cancer Environment Register. It gives only the cases of cancer for different sites. From Statistics Sweden we received the mortality

Accepted 7 September 1987
Table 1 Year of birth of the car mechanics

\begin{tabular}{lc}
\hline Year of birth & No \\
\hline-1890 & 38 \\
$1891-1900$ & 493 \\
$1901-1910$ & 1587 \\
$1911-1920$ & 2948 \\
$1921-1930$ & 4755 \\
$1931-1940$ & 7420 \\
$1941-1945$ & 4664 \\
\hline
\end{tabular}

for each age class and calendar year between 1961 and 1970 and could subsequently calculate the personyears for this period. By assuming the same mortality as the general population we estimated the personyears for 1971 to 1979 . The expected number of cases was then calculated by multiplying national incidence rates with the corresponding person-years stratifying for age, class, and calendar year. When using the data from the Cancer Environment Register we restricted the analysis to between ages 20 and 69 . The linkage between the death register and the census contains all ages.

\section{Results and discussion}

There was only one case of mesothelioma in the cancer register and none in the death register. This was a 42 year old car mechanic who was diagnosed in 1978. He had also worked in the construction industry at least since 1965 but his medical record contained no information on total work history or possible exposure to asbestos. Between 1961 and 1973, 741 mechanics had died versus 776 expected. Of these, 187 had died of cancer versus 154 expected ( $p<0.01$ ) whereas 39 had died of lung cancer compared with 23 expected $(p<0.01)$.

Table 2 Cancer morbidity in car mechanics 1961-79 in men aged 20-69 compared with the male general popullation

\begin{tabular}{|c|c|c|c|c|c|c|}
\hline \multirow[b]{2}{*}{ Form of cancer } & \multicolumn{2}{|l|}{$1961-70$} & \multicolumn{2}{|l|}{$1971-9$} & \multicolumn{2}{|l|}{$1961-79$} \\
\hline & Observed & $\overline{\text { Expected }}$ & Observed & Expected & Observed & Expected \\
\hline $\begin{array}{l}\text { All } \\
\text { Lung cancer } \\
\text { Mesothelioma } \\
\text { Stomach cancer }\end{array}$ & $\begin{array}{r}265 \\
30 \\
0 \\
15\end{array}$ & $\begin{array}{c}249 \cdot 7 \\
25 \cdot 8 \\
2^{*} \\
22 \cdot 6\end{array}$ & $\begin{array}{r}396 \\
63 \\
1 \\
29\end{array}$ & $\begin{array}{c}388 \cdot 7 \\
47 \cdot 2 \\
-* \\
25 \cdot 6\end{array}$ & $\begin{array}{r}661 \\
93 \\
1 \\
44\end{array}$ & $\begin{array}{r}638 \cdot 4 \\
73 \cdot 0 \\
-* \\
48 \cdot 2\end{array}$ \\
\hline
\end{tabular}

*Rates not available for calculation of expected incidence. 
The cancer morbidity shown in table 2 also includes stomach cancer for comparison. Thus the data indicate no increased risk of mesothelioma in car mechanics but a possibly higher risk of lung cancer compared with the general population. There are, however, several confounders that may explain this increase of lung cancer. The smoking habits of car mechanics may be heavier than those of the general population. The car mechanics may also be exposed to air pollutants other than asbestos such as exhaust gases, chromate containing paints, or lubricants. None of these factors can be ruled out as a possible explanation and this type of linkage study cannot answer the question. car mechanics, however, form a large occupational group and even a slight increase of a common cancer such as lung cancer means several cases. It therefore seems reasonable to study whether the occupational exposure of car mechanics causes an increased risk of lung cancer in more detail.

We acknowledge the support from the Swedish Metalworkers Union and the Swedish Work Environment Fund and the cooperation with Mr Rolf Ählberg. 